\title{
EDITORIAL
}

\section{Looking beyond the prevalence of depression in Brazil: are we prepared to go further?}

\author{
Laura H. Andrade, Yuan-Pang Wang \\ Department and Institute of Psychiatry (LIM-23), School of Medicine, Universidade de São Paulo, São Paulo, SP, Brazil.
}

Since the launch of the Global Burden of Disease project in 1990, the emphasis placed on common causes of mortality has shifted to chronic disabling conditions, with mental disorders emerging as one of the major cause of years living with disability (YLD). Unipolar major depression was predicted to be the second leading cause of disability-adjusted life years (DALYs) by 2020. At that time, the level of evidence was very limited, particularly in low and middle-income countries, where no or very few comparable data were available. Most population-based studies were conducted in Western developed countries. ${ }^{1}$

Most of what was said in the 1990s continues to be applicable in Brazil, as shown is this systematic review and meta-analysis by Silva et al. $^{2}$ The authors have undertaken an important effort to update the scenario of depression morbidity among Brazilian adults by demonstrating the high prevalence of depression in the country. The review underlines that most of the 27 retained studies were conducted in urbanized areas and in states of the Southeast and South regions. This may have somewhat reproduced the global situation, as most studies on the impact of depression are still being conducted in wealthier regions. ${ }^{3}$

The scarcity of high-quality data from Brazil may explain the authors' decision to include not only studies that used diagnostic instruments, but also studies that used symptom scales to screen for depressive morbidities. Indeed, 11 different screening tools were used to assess depression morbidity. Using such symptom scales may inflate the overall prevalence rate of depression, due to high sensitivity, with an impact on the accuracy of the estimate. ${ }^{3}$

High heterogeneity was found across the available estimates of depression in Brazil. $^{2}$ It is hard to decide whether this heterogeneity was due to methodological between-study variability (such as a plethora of symptoms scales and differences in the age and sex profiles of the surveyed samples) or to substantive differences in the estimate that would be expected in a continental country such as Brazil, with huge cultural diversity.

The authors attempted to address this issue by advocating the need for standardization of future

Correspondence: Laura Helena Andrade, Department \& Institute of Psychiatry (LIM-23), School of Medicine, Universidade de São Paulo, Rua Dr. Ovídio Pires de Campos, 785, CEP 05403-010, São Paulo, SP, Brasil.

E-mail: Ihsgandr@usp.br research with a validated tool in a nationwide survey. We share this opinion, but one should not neglect potential pitfalls of such an undertaking. Important initiatives, such as the World Mental Health Survey (WMHS) Consortium, endeavored to overcome this methodological concern. ${ }^{3}$ Despite this multi-country effort to standardize diagnostic criteria, interview procedures, and quality control, the prevalence estimate of major depression varied considerably between WMHS surveys. Even in this cross-national survey, it was not possible to decide whether these differences were true or methodologically driven. ${ }^{4}$

Certainly, the challenging proposal of expanding data coverage with a validated tool in less under-represented populations is an urgent need. Regarding data coverage, the suggestion of using the well-known population-based data source on housing, migration, education, employment, and fertility in Brazilian, the National Household Sample Survey (PNAD, IBGE), ${ }^{5}$ is appealing. This idea is in line with suggestions advanced by the investigators of the GBD 2010 project (e.g., Baxter et al., 2013 ${ }^{6}$ ) of including measurements of psychiatric morbidity into global surveillance systems to monitor the major causes of disability. Though this proposal is crucial, given the scarcity of data on mental morbidity, the lack of standardized indicators for the large group of mental disorders, as pointed out by Baxter et al., ${ }^{6}$ hampers the development of a comprehensive global health agenda.

This systematic review has put in perspective that much remains to be done in Brazil regarding our knowledge of the impact of depression on the population. Besides broadening coverage to other regions in order to enable between-region comparisons associated with data on clinical relevance, next steps in Brazil could include exploration of minority populations (e.g., indigenous and riverine populations) and micro-areas with particular socio-cultural aspects.

Furthermore, taking advantage of the established framework of the PNAD - a nationwide and urban-rural representative survey covering approximately 150,000 households and over 350,000 individuals across the 27 federal units of Brazil and nine metropolitan areas - may provide improved information on chronic conditions, a topic in which mental illness deserves a central place.

\section{Disclosure}

The authors report no conflicts of interest. 


\section{Reference}

1 Murray CJL, Lopez AD. The global burden of disease [Internet]. A comprehensive assessment of mortality and disability from diseases, injuries, and risk factors in 1990 and projected to 2020 [cited 2014 May 8]. Harvard University Press: Cambridge; 1996. https://extranet. who.int/iris/restricted/bitstream/10665/41864/1/0965546608_eng.pdf

2 Silva MT, Galvao TF, Martins SS, Pereira MG. Prevalence of depression morbidity among Brazilian adults: a systematic review and meta-analysis. Rev Bras Psiquiatr. 2014;36:262-70.

3 Ferrari AJ, Somerville AJ, Baxter AJ, Norman R, Patten SB, Vos T, et al. Global variation in the prevalence and incidence of major depressive disorder: a systematic review of the epidemiological literature. Psychol Med. 2013;43:471-81.

4 Bromet E, Andrade LH, Hwang I, Sampson NA, Alonso J, de Girolamo G, et al. Cross-national epidemiology of DSM-IV major depressive episode. BMC Med. 2011;9:90.

5 Instituto Brasileiro de Geografia e Estatística (IBGE). National household sample survey. Summary of indicators 2006 [Internet]. [cited 2014 Apr 29] http://www.ibge.gov.br/english/estatistica/ populacao/trabalhoerendimento/pnad2006/default.shtm

6 Baxter AJ, Patton G, Scott KM, Degenhardt L, Whiteford HA. Global epidemiology of mental disorders: what are we missing? PLoS One. 2013;8:e65514. 